\title{
Strategi Pengembangan Lembaga Keuangan Mikro Syariah (Studi Kasus pada BMT Tawfin Jakarta)
}

\author{
Development Strategy of Islamic Microfinance Institusion \\ (Case Study at BMT Tawfin Jakarta)
}

\author{
Ahmad Sapudin ${ }^{1}$, Mukhamad Najib ${ }^{2}$, Setiadi Djohar ${ }^{3}$ \\ ${ }^{1}$ Mahasiswa Pascasarjana Manajemen Bisnis Institut Pertanian Bogor, Email: \\ ahmad.sapudin@gmail.com \\ ${ }^{2}$ Dosen Pascasarjana Manajemen Bisnis Institut Pertanian Bogor, Email: mnajib23@yahoo.com \\ ${ }^{3}$ Dosen Pascarjana Sekolah Tinggi Manajemen PPM, Email: std@ppm-manajemen.ac.id
}

\begin{abstract}
This research was conducted to analysis the development strategy of Islamic microfinance institutions at BMT Tawfin, Jakarta. The aims of this research were 1) identifying health performance of BMT Tawfin based on health assessment model from Ministry of Cooperatives and Small and Medium Enterprises 2) identifying internal and external strategic factors that may influence BMT Tawfin in business development, 3) arrange appropriate formulation and alternative strategy for development of BMT Tawfin in microfinance bussines. Primary data and secondary data were gathered at this research. The research was also conducted using several analytical methods such as health assessment analysis, internal factor evaluation (IFE) and external factor evaluation (EFE) matrix, internal-external(IE) matrix, SWOT and blue ocean strategy (BOS). Based on the health assessment performance analysis, BMT Tawfin obtained score of 51,70 which was in under supervisory criteria. According to the IFE and EFE matrix results, the differences of each weighted values were 2,497 and 2,010 respectively, so the position of the BMT Tawfin in the IE matrix was situated at quadrant V. Therefore BMT Tawfin needs to use a hold and maintain strategy. Based on SWOT matrix result, priority strategies that can be implemented by BMT Tawfin was weakness - oportunities (WO) strategy. The BOS sequenced the new proposed 5 strategy priority. The result of the research showed new proposed strategy has eligibility as the blue ocean strategy (BOS).
\end{abstract}

Keywords: BMT Tawfin, blue ocean strategy (BOS), matrix, strategy

\begin{abstract}
Abstrak. Penelitian ini dilakukan untuk analisis strategi pengembangan lembaga keuangan mikro syariah pada BMT Tawfin, Jakarta. Tujuan penelitian ini adalah 1) mengidentifikasi kinerja kesehatan BMT Tawfin berdasarkan model penilaian kesehatan dari Kementerian Koperasi dan Usaha Kecil Menengah 2) mengidentifikasi faktor-faktor strategi internal dan eksternal yang memengaruhi pengembangan usaha BMT Tawfin, 3) menyusun rumusan dan alternatif strategi yang tepat untuk pengembangan BMT Tawfin dalam pembiayaan usaha mikro. Data yang diperoleh pada penelitian ini adalah data primer dan data sekunder. Penelitian ini juga dilakukan dengan menggunakan beberapa metode analisis seperti analisis penilaian kinerja kesehatan, matriks evaluasi faktor internal (IFE) dan evaluasi faktor eksternal (EFE), matriks internal-eksternal (IE), SWOT dan strategi samudra biru atau blue ocean strategy (BOS). Berdasarkan analisis penilaian kinerja kesehatan, BMT Tawfin memperoleh skor 51,70 yang termasuk dalam kriteria dalam pengawasan. Berdasarkan hasil matriks IFE dan EFE, perbedaan nilai tertimbang masing-masing adalah 2.497 dan 2.010, sehingga posisi BMT dalam matriks IE terletak pada kuadran V. Dengan demikian BMT Tawfin perlu menggunakan strategi menjaga dan mempertahankan. Berdasarkan hasil matriks SWOT, strategi prioritas yang dapat dilaksanakan oleh BMT Tawfin adalah strategi WO (weakness - opportunities). BOS merangkai prioritas 5 usulan strategi baru. Hasil penelitian menunjukkan strategi baru yang diajukan memiliki kelayakan sebagai strategi samudra biru (BOS).
\end{abstract}

Kata kunci : BMT Tawfin, BOS, matriks, strategi 


\section{Pendahuluan}

Krisis ekonomi yang melanda Indonesia dimulai pada akhir 1997 hingga akhir tahun 1998, mengakibatkan guncangan yang cukup dahsyat pada perekonomian Indonesia yang berdampak pada terganggunya stabilitas bangsa secara mikro dan makro. Pada saat itu pelaku Usaha Mikro Kecil Menengah (UMKM) dapat terhindar dan mengatasi krisis tersebut. Seperti yang dipaparkan oleh Anuraga dan Sudantoko (2002) dalam penelitian 225.000 UMKM diperoleh 64,10\% UMKM memiliki kemampuan bertahan usaha yang lebih kuat terhadap situasi perekonomian yang sedang terpuruk dan hanya $4 \%$ mengalami kebangkrutan. Hal tersebut disebabkan usaha mikro bukan usaha yang padat modal, tetapi padat karya dan lebih banyak menggunakan sumber daya lokal. Jumlah UMKM di Indonesia berdasarkan data Badan Pusat Statistik tahun 2013 mengalami kenaikan setiap tahun dengan tingkat pertumbuhan rata-rata mencapai $2,43 . \%$ dalam lima tahun terakhir. Pada tahun1998 jumlah UMKM sebanyak 36,81 juta dan mengalami peningkatan setiap tahun dan pada tahun 2012 jumlah UMKM menjadi 56,53 juta atau naik 52,02\% dari tahun 1998.

Perkembangan UMKM di Indonesia didukung oleh latar belakang pelaku UMKM. Sebagian besar pelaku UMKM mempunyai alasan berusaha karena adanya peluang bisnis dan pangsa pasar yang aman dan besar dan sebagian kecil karena faktor keturunan dan tidak ada kesempatan di bidang lain (Tambunan 2009). UMKM di Indonesia mempunyai peran yang sanga penting diantaranya menciptakan lapangan pekerjaan dan menghasilakan nilai tambah, Najib dan Kiminami (2011). Namun demikian UMKM juga menghadapi berbagai permasalahan dalam menjalankan usaha. Menurut Aslichan et al. (2009) perkembangan UMKM menghadapi masalah mendasar yang secara garis besar mencakup : (1) masih sulitnya akses UMKM pada pasar atas produk-produk yang dihasilkannya, (2) masih lemahnya pengembangan dan penguatan usaha serta (3) keterbatasan akses terhadap sumber-sumber pembiayaan dari lembaga-lembaga keuangan formal khususnya perbankan. Berdasarkan data statistik perbankan Indonesia posisi 30 September 2015 menunjukkan jumlah penyaluran kredit perbankan sebesar 3.956 triliun rupiah dengan porsi penyaluran kredit untuk UMKM sebesar 753 triliun rupiah atau 19\% dari jumlah kredit perbankan. Hal ini menunjukkan masih kecilnya porsi pembiayaan untuk UMKM. Selain itu porsi LKM Syariah dibandingkan dengan LKM Konvensional dalam pembiayaan UMKM masih kecil yaitu Rp8,03 milyar pada posisi April 2016 untuk 11 LKM atau rata-rata untuk masing-masing LKM sebesar Rp0,73 milyar dibandingkan dengan LKM Konvensional dengan total pinjaman yang diberikan sebesar Rp117,4 milyar atau rata-rata untuk masing-masing LKM sebesar Rp2,55 miliar.

Berdasarkan kondisi tersebut, lembaga keuangan mikro mempunyai fungsi strategis sebagai lembag keuangan alternatif bagi UMKM dalam memperoleh pendaanan selain pendanaan dari perbankan. Salah satu lembaga keuangan mikro syariah yang menyediakan pendanaan bagi UMKM adalah Baitul Mal wa Tamwil (BMT). BMT adalah lembaga keuangan mikro syariah (LKMS) yang tumbuh dari masyarakat dan berkembang sangat pesat. BMT memiliki peranan yang sangat strategis dalam pemberbedayaan masyarakat, khususnya masyarakat lapisan bawah serta peranannya menjauhkan masyarakat dari praktik ribawi.

Salah satu BMT yang beroperasi di wilayah Jakarta yaitu BMT Tawfin, yang berbadan hukum sebagai Koperasi Simpan Pinjam dan Pembiayaan Syariah (KSPPS). BMT Tawfin berdiri dan mulai beroperasi mulai tahun 2012 dan mengalami kondisi pasang surut dalam usahanya selama 4 tahun terakhir. Kinerja BMT Tawfin positif dan perkembangan yang pesat selama periode 2012 - 2014 dengan kenaikan aset yang dimiliki selama 3 tahun 
sebesar Rp553 juta atau 533\%, dengan nilai aset tahun 2012 sebesar Rp104 juta, tahun 2013 sebesar Rp309 juta, dan tahun 2014 sebesar Rp656 juta. Di sisi pendapatan selama 3 tahun periode 2012 - 2014 mengalami kenaikan yang signifikan. Pendapatan tahun 2013 meningkat Rp61 juta atau 321\% menjadi Rp79 juta dibandingkan dengan pendapatan tahun 2012 sebesr Rp18 juta. Tahun 2014, pendapatan meningkat Rp97 juta atau 122\% menjadi Rp176 juta dari pendapatan tahun 2013. Namun pada tahun 2015, aset dan pendapatan BMT Tawfin mengalami penurunan yang signifikan dengan penurunan aset sebesar Rp344 juta atau 52\% menjadi Rp312 juta dan pendapatan sebesar Rp59 juta atau 33\% menjadi Rp117 juta. Disisi lain, beban operasi mengalami kenaikan setiap tahun sebesar Rp18 juta atau 58\% (2013), Rp44 juta atau 91\% (2014) dan Rp34 juta atau 38\% (2015). Demikian pula Sisa Hasil Usaha (SHU) mengalami kondisi peningkatan Rp37 juta atau 215\% (2013) dan Rp12 juta atau 60\% (2014) dan mengalami penurunan pada 2015 sebesar Rp77 juta atau $240 \%$.

Berdasarkan hal di atas, tujuan penelitian adalah 1) mengidentifikasi kinerja kesehatan BMT Tawfin berdasarkan model penilaian kesehatan dari Kementerian Koperasi dan Usaha Kecil Menengah, 2) mengidentifikasi faktor-faktor strategi internal dan eksternal yang mempengaruhi pengembangan usaha BMT Tawfin, 3) menyusun rumusan dan alternatif strategi yang tepat untuk pengembangan BMT Tawfin dalam pembiayaan usaha mikro.

\section{Tinjauan Pustaka}

\subsection{Lembaga Keuangan Mikro Syariah}

Definisi Lembaga Keuangan Mikro (LKM) sesuai dengan Undang-Undang No. 1 tahun 2013 adalah lembaga keuangan yang khusus didirikan untuk memberikan jasa pengembangan usaha dan pemberdayaan masyarakat, baik melalui pinjaman atau pembiayaan dalam usaha skala mikro kepada anggota dan masyarakat, pengelolaan simpanan, maupun pemberian jasa konsultasi pengembangan usaha yang tidak sematamata mencari keuntungan. Sedangkan LKM Syariah (LKMS) adalah LKM yang menggunakan prinsip-prinsip Syariah. Menurut Aslichan (2009), terdapat perbedaan mendasar antara LKM Konvensional dengan LKM Syariah yaitu 1) LKM Syariah menerapkan sistem bagi hasil dengan nasabahnya dan tidak menerapkan segala bentuk transaksi pinjam meminjam uang yang dikenakan bunga, 2) Hubungan partisipasi dalam menanggung risiko dan menerima hasil dari suatu perjanjian bisnis merupakan hubungan antara LKM Syariah dengan nasabahnya tidak berdasarkan hubungan debitur-kreditur, 3) LKM Syariah memisahkan kedua jenis pendanaan supaya dapat dibedakan antara hasil yang diperoleh dari dana sendiri dengan hasil yang diperoleh dari dana simpanan yang diterimanya atas dasar prinsip bagi hasil, 4) LKM Syariah memberikan layanan atas dasar kemitraan seperti mudharabah dan musyarakah, atas dasar jual beli (murabahah) atau atas dasar sewa (ijarah) dan tidak memberikan layanan pinjaman dengan bunga dalam bentuk uang tunai, 5) LKM Syariah merupakan lembaga keuangan multiguna karena berperan sebagai LKM komersial, LKM investasi dan pembagunan dan 7) LKM Syariah bekerja di bawah pengawasan Pengawas Syariah.

\subsection{Baitul Mal wa Tamwil (BMT)}

Definisi Baitul Mal wa Tamwil menurut bahasa yaitu rumah dana dan rumah usaha, sedangkan pengertian yang menyeluruh bahwa BMT merupakan organisasi bisnis yang berperan sosial (Ridwan 2004). BMT atau Balai Usaha Mandiri Terpadu adalah lembaga keuangan mikro yang dioperasikan dengan prinsip bagi hasil, menumbuhkembangkan bisnis usaha mikro dalam rangka mengangkat derajat dan martabat serta membela 
kepentingan kaum fakir miskin, ditumbuhkan atas prakarsa dan modal awal dari tokohtokoh masyarakat setempat dengan berlandaskan pada sistem ekonomi yang salaam keselamatan (berintikan keadilan), kedamaian dan kesejahteraan, Sholihin (2010). Andriani dalam Hamzah et al. (2013) menjelaskan bahwa BMT merupakan lembaga pembiayaan kecil yang beroperasi menggunakan konsep campuran "Baitul Maal" dan "Baitul Tamwil" dengan target difokuskan pada sektor usaha kecil. Dari beberapa definisi BMT tersebut di atas dapat ditarik kesimpulan bahwa BMT mempunyai dua karakteristik yaitu sebagai lembaga bisnis yang bertujuan meningkatkan kualitas usaha ekonomi dan kesejahteraan anggota dan masyarakat juga sebagai lembaga sosial yang menggalang dan menyalurkan zakat, infaq, sedekah dan wakaf (ZISWAF).

\subsection{Manajemen Strategi salam Perspektif Islam}

Saat ini, manajemen strategi konvensional banyak digunakan oleh institusi atau lembaga. Definisi manajemen strategi seperti yang diungkapkan oleh Steiner dalam McConnel (2014) menyatakan bahwa strategi untuk menjawab pertanyaan dalam persaingan: (a) apa yang yang harus suatu organisasi lakukan (b) apa akhir dari pencarian dan (c) bagaimana mencapainya. Lebih lanjut McConnel (2014) mendefinisikan strategi meliputi usaha sebuah organisasi untuk mencapai tujuan dalam jangka panjang dan perencanaan sarana untuk mencapai tujuan tersebut. Menurut David (2015), manajemen strategi merupakan kombinasi antara seni dan keilmuan untuk memformulasikan, mengimplementasikan dan mengevaluasi keputusan antar fungsi suatu organisasi agar organisasi dapat mencapati tujuannya. Adapun proses manajemen strategi terdiri dari tiga tahapan utama yaitu perumusan strategi, implementasi strategi dan evaluasi strategi, Hubeis dan Najib (2008). Sedangkan, manajemen strategi dalam perspektif Islam, menurut Fontaine dan Ahmad (2013) sebagai strategi dalam mengatasi permasalahan-permasalahan mendasar yaitu penggunaan pinjaman berbasis bunga untuk membiayai entitas, pengembangan organisasi untuk berkelanjutan dalam jangka panjang, penerapan perilaku individu dalam organisasi, dan konflik antara kepentingan individu versus kepentingan seluruh organisasi.

\subsection{Strategi Samudra Biru (Blue Ocean Strategy / BOS)}

Persaingan yang sengit antar pelaku industri dalam memperebutkan pangsa pasar, mengharuskan perusahaan menyusun strategi untuk mempertahankan dan sedapat mungkin meningkatkan pangsa pasarnya. Kondisi seperti ini oleh Kim dan Mouborgne (2015) disebut dengan istilah Samudra Merah (Red Ocean). Sedangkan Samudra Biru (Blue Ocean) merupakan kondisi kebalikan dari Samudra Merah (Red Ocean). Pada samudra biru menurut Kim dan Mouborgne (2015) merujuk pada indsutri atau pasar yang belum ada saat ini, suatu pasar yang belum ditemukan sehingga belum dijamah oleh persaingan. Fakta dalam bisnis, berenang dengan sukses di samudra merah dengan cara mengalahkan pesaing akan selalu menjadi hal penting. Kondisi pasokan yang melebihi permintaan di sebagian besar industri, meski perlu berkompetisi meraih pangsa dari pasar yang berkontraksi, tidak akan memadai untuk mendukung kinerja prima, Hamel dan Prahalad dalam Chadiq (2009). Dalam samudra biru, permintaan diciptakan bukan untuk diperebutkan sehingga besarnya pasar dan permintaan di pasar tersebut tidak terbatas. Samudra biru adalah area baru yang diciptakan dengan kreativitas dan imajinasi. Di samudra biru inilah perusahaan menciptakan aturan main sendiri, menciptakan pasar sendiri dan membuat kompetisi berikut kompetitor yang saling bersaing menjadi tidak lagi relevan karena aturan-aturan permainan baru akan dibentuk 


\section{Metode Penelitian}

\subsection{Lokasi dan Waktu Penelitian}

Lokasi penelitian dilakukan pada BMT Tawfin yang terletak di wilayah Jakarta. Waktu yang dibutuhkan untuk penelitian ini dimulai pada bulan Mei hingga Agustus 2016. Dua jenis data yang digunakan dalam penelitian ini yaitu data primer dan data sekunder. Data primer diperoleh melalui wawancara mendalam dengan responden internal yang dipilih yaitu pengurus dan pengelola. Sedangkan data sekunder diperoleh melalui studi literatur dan mengakses data dan laporan.

\subsection{Jenis dan Sumber Data}

Jenis dan sumber data yang digunakan yaitu data primer dan data sekunder. Data primer diperoleh dengan wawancara langsung dengan para responden. Responden yang dipilih dalam penelitian ini menggunakan metode purposive sampling. Penentuan responden memiliki kompetensi pada bidang yang akan diteliti serta sudah berpengalaman dalam organisasi BMT. Responden adalah pengurus dan manajemen BMT Tawfin. Selanjutnya, data sekunder diperoleh untuk melengkapi data primer melalui studi literatur dan mengakses data dan laporan.

\subsection{Metode dan Analisis Data}

Data kuantitatif dan kualitatif dianalisis secara deskriftif yang disajikan dalam bentuk tabel, gambar dan matriks. Tahapan dalam analisis data berupa mengidentifikasi faktor strategis internal dan eksternal organisasi yang mempengaruhi organisasi berdasarkan analisis kinerja kesehatan, observasi langsung, dan wawancara, melakukan penilaian terhadap lingkungan internal organisasi dengan matriks IFE dan lingkungan eksternal dengan mengunakan matriks EFE. Penilaian tersebut meliputi pembobotan dan penentuan peringkat terhadap tiap faktor strategis yang diperoleh. Dari hasil penelitian masing-masing tersebut selanjutnya dibuat interpretasi, melakukan analisis dengan menggunakan matriks IE untuk mengetahui posisi organsasi berdasarkan matriks IFE dan matriks EFE yang telah diperoleh, melakukan analisis SWOT untuk memperoleh alternatif strategi berdasarkan penyesuaian faktor strategis internal dan eksternal organisasi, menyusun alternatif strategi yang dihasilkan dari matriks IE dan SWOT, dan melakukan analisis prioritas strategi yang direkomendasikan kepada organisasi dengan menggunakan matriks BOS.

\section{Hasil dan Pembahasan}

\subsection{Analisa Kinerja Kesehatan BMT Tawfin}

Penilaian kesehatan BMT Tawfin mengacu pada Peraturan Deputi Bidang Pengawasan Kementerian Koperasi dan Usaha Kecil Menengah (KUKM) nomor 07/Per/Dep.6/IV/2016 diperoleh skor sebesar 51,70 dengan kriteria Dalam Pengawasan yang termasuk dalam kriteria tidak sehat. Perhitungan tersebut diperoleh atas penilaian 8 aspek kesehatan. Aspek kesehatan pertama adalah permodalan yang memperoleh predikat sehat dengan penilaian yang berasal dari rasio modal sendiri terhadap total asset sebesar $46,26 \%$ dan rasio kecukupan modal sebesar 48,70\% . Kualitas aktiva produktif merupakan aspek kesehatan kedua yang terdiri dari 3 rasio yaitu rasio tingkat piutang dan pembiayaan bermasalah terhadap jumlah piutang dan pembiayaan sebesar 53,59\% dengan kriteria tidak lancar. Rasio kedua yaitu rasio portfolio terhadap piutang berisiko dan pembiayaan berisiko sebesar 67,01\% dengan kriteria sangat beresiko dan terakhir rasio Penyisihan Penghapusan Aktiva Produktif (PPAP) terhadap Penyisihan Penghapusan Aktiva Produktif Yang Wajib Dibentuk (PPAWD) sebesar 6,03\% dengan kriteria macet. Aspek kesehatan ketiga berupa 
manajemen yang memperoleh skor sebesar 10,90\% dengan kriteria cukup baik. Sedangkan aspek kesehatan keempat berupa efisiensi yang terdiri dari 3 rasio yaitu rasio biaya operasional terhadap pelayanan sebesar 107,30\% dengan kriteria tidak efisien. Rasio kedua yaitu rasio aset tetap terhadap total aset sebesar $0,99 \%$ berada pada kriteria baik dan rasio efisiensi pelayanan sebesar 36,65\% berada pada rasio di bawah 50\% dengan kriteria tidak baik. Likuiditas merupakan aspek kesehatan kelima yang terdiria dari rasio kas sebesar 9,5\% berada pada rasio dengan kriteria tidak likuid dan rasio pembiayaan sebesar 9,5\% dengan kriteria cukup likuid. Aspek kesehatan keenam berupa kemandirian dan pertumbuhan yang terdiri dari 3 rasio yaitu rasio rentabilitas aset sebesar $-14,37 \%$, rasio rentabilitas ekuitas sebesar $-6,74 \%$ dan rasio kemandirian operasional sebesar $64,42 \%$ yang seluruhnya memperoleh kriteria rendah. Jati diri koperasi merupakan aspek kesehatan ketujuh yang terdiri dari rasio promosi ekonomi anggota sebesar -40,78\% dengan kriteria tidak bermanfaat dan rasio partisipasi bruto sebesar $100 \%$ dengan kriteria tinggi. Kepatuhan prinsip syariah merupakan aspek kesehatan terakhir memperoleh skor 7 dengan kriteria cukup patuh.

\section{Analisa Matriks IFE, EFE dan IE}

Hasil identifikasi faktor strategis internal dan eksternal diperoleh 32 faktor terdiri dari masing-masing 8 faktor kekuatan, kelemahan, peluang dan ancaman. Hasil skor nilai-nilai faktor strategis internal BMT Tawfin sebesar 2,497 yang berarti memiliki posisi internal yang lemah (David 2015) dengan rincian hasil pada Tabel 1.

\section{Tabel 1 Hasil Skor Internal Factor Evaluation (IFE)}

\begin{tabular}{|c|c|c|c|}
\hline \multicolumn{3}{|c|}{ Internal Factor Evaluation (IFE) } & 2,497 \\
\hline Kekuatan (Strengths) & Skor & Kelemahan (Weaknesses) & Skor \\
\hline Proses dan syarat pembiayaan & 0,239 & Pembiayaan bermasalah & 0,075 \\
\hline $\begin{array}{l}\text { Pelayanan kepada anggota dan } \\
\text { nasabah }\end{array}$ & 0,219 & Jumlah tenaga pemasaran & 0,093 \\
\hline $\begin{array}{l}\text { Pelaksanaan dan penerapan prinsip } \\
\text { syariah }\end{array}$ & 0,219 & Ketersediaan modal (likuiditas) & 0,102 \\
\hline Produk yang ditawarkan & 0,190 & Sarana dan prasarana & 0,112 \\
\hline Sistem pembukuan & 0,188 & Lokasi usaha & 0,127 \\
\hline $\begin{array}{l}\text { Pengawasan manajemen dan } \\
\text { prinsip syariah }\end{array}$ & 0,180 & yang dilakukan & 0,137 \\
\hline Tingkat turnover karyawan & 0,172 & Kompetensi SDM & 0,138 \\
\hline $\begin{array}{l}\text { Pembinaan dan pendampingan } \\
\text { usaha nasabah }\end{array}$ & 0,170 & $\begin{array}{l}\text { Pembinaan, pendidikan dan } \\
\text { pelatihan SDM }\end{array}$ & 0,139 \\
\hline Total Kekuatan (Strengths) & 1,576 & Total Kelemahan (Weaknesses) & 0,922 \\
\hline
\end{tabular}

Sedangkan hasil skor nilai-nilai faktor strategis internal BMT Tawfin sebesar 2,010 yang berarti BMT Tawfin memanfaatkan peluang yang ada atau menghindari ancaman yang muncul dengan respon rata-rata (David 2015) dengan rincian pada Tabel 2. 
Tabel 2 Hasil Skor External Factor Evaluation (EFE)

\begin{tabular}{|c|c|c|c|}
\hline \multicolumn{3}{|c|}{ Eksternal Factor Evaluation (EFE) } & \multirow{2}{*}{$\begin{array}{l}2,010 \\
\text { Skor }\end{array}$} \\
\hline Peluang (Opportunities) & Skor & Ancaman (Threats) & \\
\hline Pelaku usaha mikro yang & & & \\
\hline $\begin{array}{l}\text { berminat terhadap layanan } \\
\text { koperasi }\end{array}$ & 0,245 & $\begin{array}{l}\text { Biaya perolehan pendanaan dari } \\
\text { lembaga perbankan }\end{array}$ & 0.261 \\
\hline Keinginan masyarakat untuk & & Kenaikan harga bahan pokok & \\
\hline menjalankan syariat Islam & 0,212 & dan tarif dasar listrik & 0,241 \\
\hline Pemahaman masyarakat terhadap & & Persaingan dengan lembaga & \\
\hline koperasi dan penerapan syariah & 0,183 & keuangan lain & 0,177 \\
\hline $\begin{array}{l}\text { Kepercayaan pihak luar sebagai } \\
\text { mitra }\end{array}$ & 0,138 & $\begin{array}{l}\text { Perkembangan kredit mikro dari } \\
\text { perbankan/ lembaga keuangan }\end{array}$ & 0,174 \\
\hline Regulasi pemerintah terhadap & & & \\
\hline KSPPS & 0,132 & & \\
\hline Pinjaman permodalan dari & & & \\
\hline $\begin{array}{l}\text { lembaga keuangan/ perbankan } \\
\text { syariah }\end{array}$ & 0,119 & & \\
\hline Program-program perkuatan dari & & & \\
\hline Pemerintah & 0,118 & & \\
\hline $\begin{array}{l}\text { Kebutuhan pembiayaan yang } \\
\text { mudah, murah dan cepat }\end{array}$ & 0,108 & & \\
\hline $\begin{array}{l}\text { Pengawasan pelaksanaan prinsip } \\
\text { syariah dari Pemerintah/ MUI }\end{array}$ & 0,099 & & \\
\hline $\begin{array}{l}\text { Perhatian pemerintah terhadap } \\
\text { pengembangan KSPPS }\end{array}$ & 0,069 & & \\
\hline $\begin{array}{l}\text { Layanan produk perbankan } \\
\text { berbasis teknologi informasi }\end{array}$ & 0,066 & & \\
\hline $\begin{array}{l}\text { Pendirian dan perkembangan } \\
\text { jaringan KSPPS melalui }\end{array}$ & & & \\
\hline $\begin{array}{l}\text { perhimpunan/asosiasi } \\
\text { Total Peluang (Opportunities) }\end{array}$ & $\begin{array}{l}0,058 \\
1,547\end{array}$ & Total Ancaman (Threats) & 0,853 \\
\hline
\end{tabular}

Berdasarkan analisis faktor internal dan eksternal melalui matriks IFE dan EFE diperoleh skor faktor-faktor strategis internal sebesar 2,497 dan faktor-faktor strategis eksternal sebesar 2,010 yang menempatkan posisi BMT Tawfin pada sel V. Menurut David (2015), sel tersebut pada Matriks IE termasuk dalam strategi menjaga dan mempertahankan (hold and maintain).

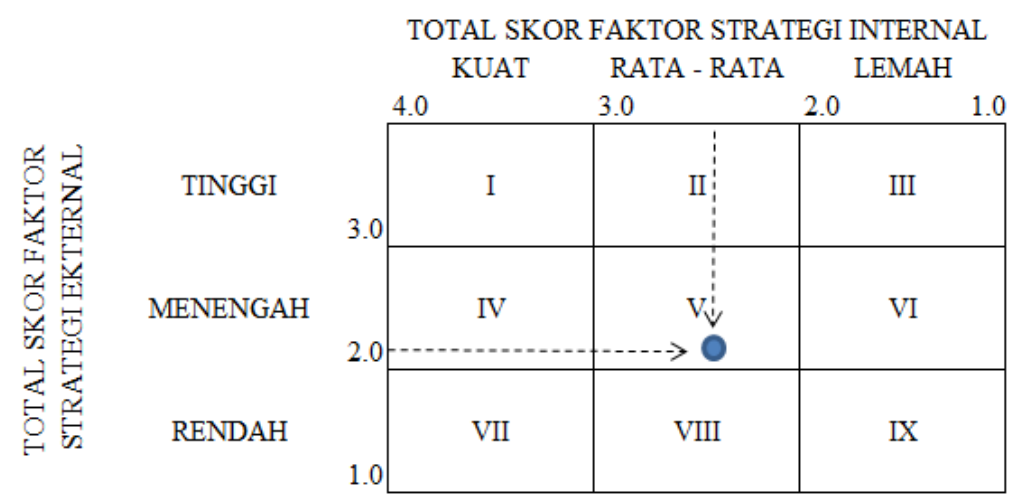

Gambar 1 Hasil Analisis Matriks Internal - Ekternal (Matriks IE) 


\section{Analisa Matriks SWOT}

Analisa matriks SWOT dengan membandingkan antara faktor eksternal berupa peluang dan ancaman dengan faktor internal berupa kekuatan dan kelemahan dalam 4 strategi (David 2015) yaitu 1) Strategi SO (Strengths - Opportunities), 2) Strategi ST (StrengthsThreats), 3) Strategi WO (Weakness-Opportunities) dan 4) Strategi WT (WeaknessThreats).

Strategi SO merupakan strategi dalam menggunakan seluruh kekuatan internal untuk memanfaatkan peluang eksternal (David 2015). Berdasarkan identifikasi faktor-faktor internal berupa kekuatan dan kelemahan dan faktor-faktor eksternal berupa peluang dan ancaman melalui matriks IFE dan EFE diperoleh 3 strategi SO yang dapat dijalankan oleh BMT Tawfin yaitu 1) Meningkatkan pencitraan BMT Tawfin terus menerus melalui peningkatan pelayanan, akuntabilitas dan tata kelola sebagai modal pengembangan KSPPS di masa mendatang, 2) Meningkatkan hubungan baik dengan Pemerintah dan MUI dalam pembinaan dan pengawasan BMT Tawfin dan 3) Memperluas layanan simpanan dan pembiayaan dengan standarisasi layananan prima dan prinsip syariah.

Pada strategi ST, BMT Tawfin menggunakan kekuatan yang dimiliki untuk mengatasi ancaman (Rangkuti, 2015). Berikut strategi ST yang dapat dijalankan oleh BMT Tawfin yaitu 1) Menetapkan marjin strategis yang mampu bersaing dengan marjin lembaga keuangan lain, 2) Berperan aktif dalam jaringan KSPPS melalui perhimpunan/ asosiasi untuk meningkatkan akses permodalan, meningkatkan standar operasi dan pemanfaatan teknologi bersama dan 3) Meningkatkan anggota baru melalui jaringan FOSSEI.

Strategi WO diterapkan berdasarkan pemanfaatan peluang yang ada dengan cara meminimalkan kelemahan yang ada (Rangkuti 2015). Berikut strategi WO yang dapat dijalankan oleh BMT Tawfin yaitu 1) Mengembangkan linkage program dengan lembaga keuangan dan perbankan syariah, 2) Menambah satu tenaga pemasaran yang memiliki kemampuan mengelola penghimpunan dan penempatan dana (funding dan lending), 3) Meningkatkan fungsi pengawasan manajemen risiko dalam kegiaatan operasi melalui perbaikan Standar Operasi Manajemen dan Standar Operasi Prosedur, pembentukan Dewan Pengawas Syariah (DPS), peningkatan penanganan pembiayaan bermasalah dan memberdayakan kembali komite-komite yang dibentuk dalam struktur organisasi, 4) Meningkatkan kompetensi SDM melalui pembinaan, pendidikan dan pelatihan yang berkelanjutan dan 5) Mengembangkan promosi melalui media online dan sosial dan meningkatkan sarana dan prasana.

Strategi WT merupakan strategi bertahan (defensive) yang diarahkan untuk mengurangi kelemahan internal dan menghindari ancaman eksternal (David 2015). Berikut strategi WT yang dapat dijalankan oleh BMT Tawfin yaitu :

1) Meningkatkan modal dari simpanan pokok dan simpanan wajib anggota,

2) Mengembangkan pembinaan anggota dan nasabah agar tetap loyal,

3) Meningkatkan efisiensi biaya operasi dengan optimalisasi sarana dan prasarana dan SDM yang dimiliki dan 4) Meningkatkan efisiensi biaya operasi dengan optimalisasi sarana dan prasarana dan SDM yang dimiliki.

Strategi yang dihasilkan matriks SWOT tersebut di atas, dipilih salah satu strategi prioritas yang akan digunakan dalam analisa BOS. Hasil analisa kinerja kesehatan dan analisa matriks internal - eksternal digunakan sebagai pertimbangan dalam pemilihan prioritas strategi tersebut. Sesuai dengan hasil analisa kinerja kesehatan BMT Tawfin diperoleh 4 aspek yang dapat menggangu kelangsungan usaha BMT Tawfin yaitu kualitas aktiva produktif dan likuiditas yang buruk, kegiatan operasi yang tidak efisien, dan kemandirian 
yang rendah. Sedangkan hasil analisa matriks internal - ekternal (IE) menunjukkan posisi BMT Tawfin berada pada sel $\mathrm{V}$ dengan strategi menjaga dan mempertahankan. Berdasarkan kondisi tersebut, prioritas strategi yang dapat dilaksanakan oleh BMT Tawfin adalah strategi WO (Weakness-Opportunities) yang telah dijelaskan di atas. Hal ini sesuai dengan pendapat David (2015), jika sebuah perusahaan memiliki kelemahan besar, maka perusahaan akan berjuang untuk mengatasinya dan mengubahnya menjadi kekuatan. Lebih lanjut, David (2015) menjelaskan bahwa organisasi pada umumnya akan menjalankan strategi WO, ST atau WT untuk mencapai situasi di mana organisasi dapat melaksanakan strategi SO. Selanjutnya strategi WO akan digunakan dalam analisa BOS sebagai strategi awalan BMT Tawfin.

\section{Strategi Kanvas}

Strategi kanvas digunakan untuk memahami dimana kompetisi saat ini sedang terjadi, dan memahami faktor-faktor apa saja yang sedang dijadikan ajang kompetisi dalam lembaga keuangan mikro. Terdapat tujuh faktor yang menentukan kesuksesan BMT Tawfin yaitu 1) besaran marjin pembiayaan, 2) besaran marjin simpanan, 3) jenis produk, 4) kompetensi SDM, 5) kemampuan permodalan (likuiditas), 6) proses dan syarat pembiayaan, dan 7) jangka waktu pembiayaan. Hasil strategi kanvas pada Gambar 2.

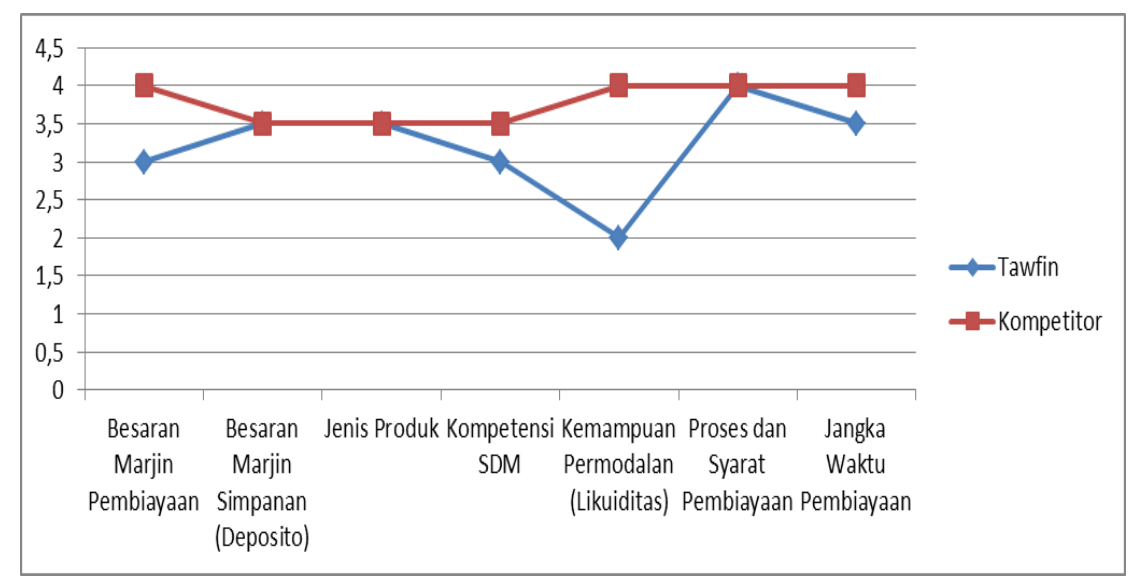

\section{Gambar 2 Kurva Nilai BMT Tawfin}

\section{Kerangka Kerja Empat Langkah dan ERRC Grid}

Pada bagian ini merupakan tahap re-formulasi pembuatan strategi samudra biru dengan kerangka kerja empat langkah (4 action framework). Penciptaan nilai baru dilakukan pertama kali dengan membuat kerangka kerja empat langkah yang terdiri dari faktor-faktor apa saja yang perlu dihapuskan, dikurangi, ditingkatkan dan diciptakan. Berdasarkan analisa kerangka kerja empat langkah, dibentuk ERRC (Eliminate, Reduce, Raise and Create) Grid atau kotak hapuskan-kurangi-tingkatkan-ciptakan untuk menciptakan strategi menuju kondisi samudera biru, hasil ERRC Grid diuraikan pada Tabel 3. 
Tabel 3 ERRC Grid

\begin{tabular}{|c|c|}
\hline Eliminate - Hapuskan & Raise - Tingkatkan \\
\hline $\begin{array}{l}\text { - Hambatan dalam memperoleh } \\
\text { permodalan dan likuiditas. }\end{array}$ & $\begin{array}{l}\text { - Kontribusi anggota, pengurus dan } \\
\text { pengawas } \\
\text { - Kompetensi, pembinaan dan } \\
\text { peningkatan kapasitas sumber daya } \\
\text { manusia. } \\
\text { - Produk yang murah dan cepat } \\
\text { - Fokus terhadap pengembangan usaha } \\
\text { sesuai dengan prinsip syariah baik dari } \\
\text { aspek sosial dan komersial }\end{array}$ \\
\hline Reduce - Kurangkan & - Create - Ciptakan \\
\hline $\begin{array}{l}\text { - Pembiayaan bermasalah } \\
\text { - Anggota yang tidak aktif memberikan } \\
\text { kontribusi. } \\
\text { - Waktu pelayanan dan penyaluran } \\
\text { pembiayaan }\end{array}$ & $\begin{array}{l}\text { - Penghargaan berbasis kinerja } \\
\text { - Sinergi yang lebih kuat dengan alumni } \\
\text { FoSSEI. } \\
\text { - Layanan teknologi informasi yang } \\
\text { dapat menjangkau dan memenuhi } \\
\text { kebutuhan anggota dan nasabah. }\end{array}$ \\
\hline
\end{tabular}

\section{New Proposed Strategy}

Pada bagian ini merupakan sintesis dari keseluruhan strategi-strategi yang diperoleh, yaitu strategi W-O (hasil matriks SWOT) dan reformulasi strategi samudra biru (strategi kanvas, 4 action framework dan ERRC Grid). New proposed strategy dihasilkan melalui rangkaian proses sintesis dalam Tabel 4.

\section{Tabel 4 Sintesis Strategi WO dengan Blue Ocean Idea}

\begin{tabular}{|c|c|c|}
\hline $\begin{array}{c}\text { Initial } \\
\text { Strategy } \\
\text { WO (P) }\end{array}$ & $\begin{array}{l}\text { + Blue Ocean Idea } \\
\text { (Strategi Kanvas, } \\
\text { Kerangka Kerja Empat } \\
\text { Langkah, ERRC Grid) }\end{array}$ & $\begin{array}{c}\text { New Proposed Strategy } \\
\text { (Initial Strategy WO }+ \text { Blue Ocean Idea) }\end{array}$ \\
\hline P1 & $\begin{array}{l}\text { Dipertajam dengan } \\
\text { tambahan dari ERRC Grid }\end{array}$ & $\begin{array}{l}\text { Menjadi: Mengembangkan linkage program } \\
\text { dengan lembaga keuangan dan perbankan } \\
\text { syariah serta bersinergi dengan alumni FOSSEI } \\
\text { dalam mendapatkan dana murah. }\end{array}$ \\
\hline P2 & $\begin{array}{l}\text { Tetap dan tidak ada } \\
\text { perubahan }\end{array}$ & $\begin{array}{l}\text { Tetap menggunakan strategi butir P2 dari } \\
\text { strategi WO. }\end{array}$ \\
\hline P3 & $\begin{array}{l}\text { Tetap dan tidak ada } \\
\text { perubahan }\end{array}$ & $\begin{array}{l}\text { Tetap menggunakan strategi butir P3 dari } \\
\text { strategi WO. }\end{array}$ \\
\hline P4 & $\begin{array}{l}\text { Dipertajam dengan } \\
\text { tambahan dari ERRC Grid }\end{array}$ & $\begin{array}{l}\text { Menjadi: Meningkatkan layanan kepada } \\
\text { anggota dan nasabah melalui peningkatan } \\
\text { sarana dan prasana terutama layanan teknologi } \\
\text { informasi yang dapat menjangkau dan } \\
\text { memenuhi kebutuhan anggota dan nasabah dan } \\
\text { pemberian produk yang murah dan cepat namun } \\
\text { tetap sesuai dengan prinsip syariah. }\end{array}$ \\
\hline P5 & $\begin{array}{l}\text { Dipertajam dengan } \\
\text { tambahan dari ERRC Grid }\end{array}$ & $\begin{array}{l}\text { Menjadi: Meningkatkan kompetensi SDM } \\
\text { melalui pelatihan dan pembinaan dan } \\
\text { memberikan penghargaan berbasis kinerja agar } \\
\text { fokus terhadap pengembangan usaha sesuai } \\
\text { dengan prinsip syariah. }\end{array}$ \\
\hline
\end{tabular}


Berdasarkan rangkaian proses Tabel 4 di atas, maka dapat dirangkum sintesis Proposal Strategi Baru (New Proposed Strategy) dari P1 sampai P5 yaitu : 1) Mengembangkan linkage program dengan lembaga keuangan dan perbankan syariah serta bersinergi dengan alumni FoSSEI dalam mendapatkan dana murah, 2) Menambah satu tenaga pemasaran yang memiliki kemampuan mengelola penghimpunan dan penempatan dana (funding dan lending), 3) Meningkatkan fungsi pengawasan manajemen risiko dalam kegiatan operasi melalui perbaikan Standar Operasi Manajemen dan Standar Operasi Prosedur, pembentukan Dewan Pengawas Syariah (DPS), peningkatan penanganan pembiayaan bermasalah dan pemberdayaan kembali komite-komite yang dibentuk dalam struktur organisasi, 4) Meningkatkan layanan kepada anggota, nasabah dan masyarakat (sosial) melalui peningkatan sarana dan prasana terutama layanan teknologi informasi yang dapat menjangkau dan memenuhi kebutuhan anggota dan nasabah, penyediaan produk jasa yang murah dan cepat namun tetap sesuai dengan prinsip syariah dan memberikan layanan penghimpunan dan pendistribusian zakat, infaq, shodaqah dan wakaf (ZISWAF) dan 5) Meningkatkan kompetensi SDM melalui pelatihan dan pembinaan dan memberikan penghargaan berbasis kinerja agar fokus terhadap pengembangan usaha sesuai dengan prinsip syariah.

BMT Tawfin sebagai lembaga keuangan mikro syariah yang menjalankan prinsip-prinsip syariah dalam seluruh kegiatannya berpedoman pada maqashid syariah. Maqashid syariah menurut Laldin dan Furqani (2013) menyediakan landasan pilosofis untuk arah dan pedoman bagi keuangan Islam. Lebih lanjut Laldin dan Furqani (2013) menjelaskan bahwa kepatuhan terhadap maqashid syariah sangat penting untuk mengembangkan keuangan Islam sebagai sistem yang menyadari kesejahteraan manusia (maslahah). Cokrohadisumarto et al. (2016) menjelaskan maqashid syariah memberikan prinsipprinsip dasar yang menjadi pegangan bagi operasional lembaga keuangan Islam termasuk BMT meliputi: bertindak atas nama Allah SWT dan Rasulullah shalallohu alaihi wasalam, berlaku adil dan bebas dari eksploitasi (yang tercermin dari pelarangan bunga), pelaksanaan dengan berbagi resiko (profit and loss sharing), pelaksanaan bisnis halal dan etis (yang tercermin dari larangan perilaku spekulatif dan perjudian), dan ta'awun (membantu yang lemah).

Pada new proposed strategy poin 1 dan 2, merupakan strategi BMT Tawfin dalam memperoleh likuiditas dan pemasaran yang dapat meningkatkan harta BMT Tawfin. Meningkatkan harta dengan tuntunan syariah merupakan implementasi dari maqashid syariah berupa terpeliharanya harta kekayaan (mal), Firdaus (2015). Menurut Hadi (2012) uang (harta) dalam Islam sebagai tulang punggung kehidupan atau bahan bakar dalam bisnis, sehingga dalam pengelolaanya pun harus diserahkan kepada seorang yang profesional (QS Annisa:5). Pada ayat lain Allah subhanahu wa ta'ala menyuruh manusia berbisnis (QS Annisa:29) dengan cara berniaga dan diperbolehkannya mendapatkan keuntungan (QS Hud:86). Menjaga dan menumbuhkan harta termasuk hal yang diperintahkan.

Pengawasan dalam Islam terbagi dalam dua yaitu pengawasan dari dalam diri sendiri yang bersumber dari tauhid dan keimanan kepada Allah subhanahu wa ta'ala dan pengawasan dari sistem (dari luar diri sendiri), Hafidhuddin \& Tanjung (2005). Lebih lanjut Hafidhuddin \& Tanjung (2005) menjelaskan bahwa sistem pengawasan yang baik tidak terlepas dari hukuman (punishment) dan imbalan (reward). Takwa merupakan pengawasan yang efektif untuk diri sendiri, seperti hadits Rasulullah shalallohu alaihi wasalam berikut: "Bertaqwalah kepada Allah dimanapun engkau berada, dan hendaknya setelah melakukan kejelekan engkau melakukan kebaikan yang dapat menghapusnya. Serta bergaulah dengan orang lain dengan akhlak yang baik" (HR. Ahmad 21354, Tirmidzi 1987). 
New proposed strategy poin 3 berupa pengawasan syariah merupakan bentuk implementasi dari maqashid syariah berupa terjaganya agama (dien). Menurut Hadi (2012), jika perusahaan menyatakan diri sebagai perusahaan Islami, maka ia harus patuh terhadap ketentuan syariah (syariah compliance) yang diwujudkan dalam identitas perusahaan. BMT Tawfin sebagai lembaga keuangan mikro syariah yang menjalankan usaha sesuai dengan prinsip syariah harus patuh pada ketentuan syariah. Dewan pengawas syariah menjalankan fungsi pengawasan agar aktivitas BMT Tawfin tetap sesuai dengan prinsip syariah.

Orientasi new proposed strategy poin 4 adalah peningkatan layanan kepada pelanggan yang terdiri dari anggota, nasabah dan masyarakat. Pelanggan merupakan faktor yang sangat penting bagi keberlanjutan organisasi, Firdaus (2015). Lebih lanjut Firdaus (2015) menjelaskan bahwa pelanggan merupakan media pembawa rizki dari Allah subhanahu wa ta'ala. Semakin dekat organisasi dengan pelanggan maka semakin besar peluang untuk mendapatkan rizki. Allah subhanahu wa ta'ala menggunakan media pelanggan untuk menghantarkan rizki, dengan tujuan agar organisasi dapat berinteraksi atau berakhlak baik terhadap pelanggan yang merupakan hubungan sosial dalam merealisasikan kewajiban manusia sebagai khalifah Allah. Pelayanan kepada pelanggan berbanding lurus dengan peningkatan pendapatan dan keuntungan. Hadi (2012) menjelaskan kesinambungan organisasi merupakan implementasi dari menjaga keturunan (nasl) pada maqashid syariah. Lebih lanjut Hadi (2012) menjelaskan ada dua hal utama yang harus dipenuhi organisasi yaitu keberkahan dan keuntungan. Keberkahan disebabkan oleh keadilan kepada semua pihak walaupun membuat rasa adil itu sulit. Wujud dari keadilan kepada stakeholder adalah kepuasan anggota, kepuasan nasabah, kepuasan masyarakat, kepuasan karyawan, dan kepuasan pengurus.

New proposed strategy poin 5 merupakan strategi BMT Tawfin dalam meningkatan kualitas sumber daya insani (SDI) yang dimiliki. Peningkatan kualitas SDI berbanding lurus dengan peningkatan pengetahuan yang berpengaruh pada peningkatkan pelayanan kepada pelanggan. Peningkatan ilmu pengetahuan SDI merupakan implementasi dari maqashid syariah menjaga akal ('aql), Hadi (2012). Selain itu peningkatan kepuasan pelanggan akan memberikan dampak peningkatan pendapatan yang akhirnya kesejahteraan pengurus dan karyawan akan meningkat. Peningkatan kesejahteraan hidup merupakan implementasi dari maqasid syariah menjaga jiwa (nafs).

\section{BOI Index}

Tahap akhir dari seluruh prinsip perumusan strategi samudra biru, yaitu verifikasi strategi baru. Kim dan Mauborgne (2005) menyebutkan bahwa blue ocean idea (BOI) Index adalah alat sederhana namun kuat untuk memverifikasi apakah ide strategi bisnis baru memenuhi kriteria dari blue ocean strategy. Hasil uji BOI Index disajikan pada Tabel 5. 
Tabel 5 Hasil BOI Indeks

\begin{tabular}{lllc}
\hline Kriteria & \multicolumn{1}{c}{ Pertanyaan } & $\begin{array}{c}\text { New } \\
\text { Current } \\
\text { Strategy }\end{array}$ & $\begin{array}{c}\text { Proposed } \\
\text { Strategy }\end{array}$ \\
\hline Utilitas & $\begin{array}{l}\text { Apakah penawaran atau ide strategi ini } \\
\text { memberikan utilitas yang luar biasa bagi } \\
\text { perusahaan? }\end{array}$ & $+/-$ & + \\
Harga/ & $\begin{array}{l}\text { Apakah penawaran atau ide strategi ini dengan } \\
\text { mudah akan mengikat pelanggan yang potensial? }\end{array}$ & + & + \\
Rate & $\begin{array}{l}\text { Apakah struktur biaya dari ide strategi ini mampu } \\
\text { memenuhi target biaya yang ditentukan? }\end{array}$ & + & + \\
Adopsi & $\begin{array}{l}\text { Apakah ide strategi ini juga mampu mengadopsi } \\
\text { rintangan rintangan yang ada di masa depan? }\end{array}$ & + & + \\
\hline
\end{tabular}

Tabel 5 menunjukkan 5 butir New Proposed Strategy memenuhi kaidah BOI Index dalam hal Utilitas, Harga, Biaya dan Adopsi. Sedangka Current Strategy BMT Tawfin 2015 hanya memenuhi kriteria Harga/ Rate kadang memenuhi Utilitas dan Biaya, serta tidak memenuhi dalam hal kriteria Adopsi. Hasil ini menunjukkan Strategi Baru (New Proposed Strategy) memiliki kelayakan sebagai Blue Ocean Strategy.

\section{Implikasi Manajerial}

Strategi pengembangan BMT Tawfin berimplikasi terhadap berbagai aspek yaitu 1) meningkatkan tata kelola (good governance) sesuai dengan misi BMT Tawfin dengan meningkatkan fungsi pengawasan manajemen risiko dan pengawasan syariah oleh DPS, 2) meningkatkan kualitas layanan dengan peningkatan kompetensi, keterampilan dan pengetahuan sumber daya insani melalui pelatihan dan pembinaan terutama dibidang pemasaran dan peningkatan teknologi informasi yang dapat memenuhi kebutuhan anggota dan nasabah, 3) meningkatkan kapasitas kelembagaan dengan menjalin kerjasama/ kemitraan yang saling menguntungkan dengan lembaga keuangan mikro syariah dan perbankan syariah serta aktif dalam asosiasi untuk dapat mengembangkan BMT dalam lingkup yang lebih luas.

\section{Simpulan dan Saran}

\subsection{Simpulan}

Berdasarkan analisis yang dilakukan dapat disimpulkan yaitu kinerja kesehatan BMT Tawfin diperoleh skor keseluruhan sebesar 51,70 dengan kriteria Dalam Pengawasan yang termasuk dalam kategori tidak sehat. Kondisi tersebut disebabkan oleh kualitas aktiva produktif dan likuiditas yang kurang baik, kegiatan operasi yang tidak efisien dan kemandirian dan pertumbuhan yang rendah. Hasil analisis faktor-faktor strategis internal dan menunjukkan posisi BMT Tawfin berada pada sel $\mathrm{V}$ dengan strategi berupa menjaga dan mempertahankan (hold and maintain). Sedangkan hasil analisa faktor-faktor strategi internal dan eksternal menggunakan matriks SWOT menghasilkan prioritas strategi berupa 5 strategi WO (Weakness - Opportunities) yang kemudian dikolaborasi dengan blue ocean strategy menghasilkan 5 strategi uslan yaitu (1) Mengembangkan linkage program dengan lembaga keuangan dan perbankan syariah serta bersinergi dengan alumni FoSSEI dalam mendapatkan dana murah, (2) Menambah satu tenaga pemasaran yang memiliki kemampuan mengelola penghimpunan dan penempatan dana (funding dan lending), (3) Meningkatkan fungsi pengawasan manajemen risiko dalam kegiatan operasi melalui perbaikan Standar Operasi Manajemen dan Standar Operasi Prosedur, pembentukan Dewan Pengawas Syariah (DPS), peningkatan penanganan pembiayaan bermasalah dan 
pemberdayaan kembali komite-komite yang dibentuk dalam struktur organisasi, (4) Meningkatkan layanan kepada anggota, nasabah dan masyarakat (sosial) melalui peningkatan sarana dan prasana terutama layanan teknologi informasi yang dapat menjangkau dan memenuhi kebutuhan anggota dan nasabah, penyediaan produk jasa yang murah dan cepat namun tetap sesuai dengan prinsip syariah dan memberikan layanan penghimpunan dan pendistribusian zakat, infaq, shodaqah dan wakaf (ZISWAF), (5) Meningkatkan kompetensi SDM melalui pelatihan dan pembinaan dan memberikan penghargaan berbasis kinerja agar fokus terhadap pengembangan usaha sesuai dengan prinsip syariah.. Hasil uji dengan BOI Index atas new proposed strategy memenuhi kaidah BOI Index sehingga memiliki kelayakan sebagai Blue Ocean Strategy yang dapat digunakan sebagai alternatif strategi yang tepat untuk pengembangan BMT Tawfin di masa yang akan datang.

\subsection{Saran}

Saran yang dapat menjadi masukan bagi BMT Tawfin dalam penelitian ini yaitu melakukan langkah-langka perbaikan berupa penyelamatan pembiayaan bermasalah dengan perpanjangan waktu pembiayaan (rescheduling) dan bantuan manajemen. Apabila kedua langkah tersebut di atas tidak dapat dilakukan, maka langkah selanjutnya dengan mengeksekusi jaminan. Pilihan langkah terakhir berupa penghapusbukuan pembiayaan (write off) untuk pembiayaan dengan kolektabilitas macet. BMT Tawfin dalam mengatasi kesulitan likuiditas perlu melakukan usaha berupa penambahan anggota baru dari alumni FOSSEI dengan meningkatkan kerjasama dengan Korps Alumni FOSSEI dan KSEI yang berada di kampus. Prioritas alumni FOSSEI yang menjadi target anggota adalah alumni yang berada di sekitar Jakarta, Bogor, Tangerang, Depok dan Bekasi (Jabodetabek). Tambahan anggota baru akan menghasilkan likuiditas murah dari simpanan pokok dan simpanan wajib. Selain itu, BMT Tawfin dapat mengikuti linkage program dengan perbankan syariah dengan model channeling yang memiliki resiko rendah untuk mengatasi likuiditas pembiayaan. Peningkatan efisiensi merupakan salah satu langka perbaikan dengan meningkatkan pendapatan diiringi dengan menjaga biaya operasionalnya. Penambahan satu orang tenaga pemasaran diharapkan dapat meningkatkan pendapatan dan produktivitas yang lebih tinggi dibandingkan dengan peningkatan biaya. Skema berbasis kinerja diterapkan untuk pemberian remunerasi bagi karyawan, sehingga efiesiensi dapat terjaga. Fungsi BMT Tawfin juga perlu ditingkatkan sebagai lembaga sosial (Baitul Mal) dengan melakukan penghimpunan dan penyaluran zakat, infaq, shodaqoh dan wakaf (ZISWAF).

\section{Daftar Pustaka}

Anuraga P, Sudantoko HD. 2002. Koperasi, kewirausahaan, dan usaha kecil. Jakarta(ID): Rineka Cipta

Aslichan, Hubeis M, Sailah I. 2009. Kajian Peniliaian Kesehatan Dalam Rangka Mengevaluasi Kinerja Lembaga Keuangan Mikro Syariah Baitul Maal wat Tamwil (Kasus BMT Bina Umat Sejahtera Lasem Rembang), Jurnal Manajemen Pengembangan Industri Kecil Menengah Sekolah Pascasarjana IPB, 4(2),195-205

[BPS] Biro Pusat Statistik. Tabel Perkembangan UMKM pada Periode 1997 -2012. [Internet]. [diunduh 2016 Januari 10]. Tersedia pada: https://www.bps.go.id/index.php/linkTabelStatis/1322.

Cokrohadisumarto WM, Ismail A.G., Wibowo K.A. 2016. BMT Praktik dan Kasus. Jakarta (ID): RajaGrafindo Persada.

Chadiq U. 2009. Implementasi Strategi Blue Ocean untuk Mencapai Kinerja Perusahaan yang Kompetitif. AKSE: Jurnal Ekonomi dan Bisnis. 4(7). 44-55. 
David FR. 2015. Strategic Management Concept and Case, Ed ke-15, Essex (UK): Pearson Education Limited.

Firdaus Ahmad. 2014. Maslahah Performa. Yogyakarta (ID):Deepublish

Fontaine R, Ahmad K. 2013. Strategic Management from an Islamic Perspective_Text and Cases. Singapore(SG): Wiley Publishing.

Hadi Kuncoro. 2012. Implementasi Maqoshid Syariah Sebagai Indikator sebagai Perusahaan Islami, Jurnal AL-Azhar Indonesia Seri Pranata Sosial, Vol. 1(3), 140150

Hafidhuddin D, Tanjung H. 2005. Manajemen Syariah Dalam Praktik. Jakarta (ID): Gema Insani.

Hamzah, Rusby Z, Hamzah Z. 2013. Analysis Problem of Baitul Maal Wat Tamwil (BMT) Operation in Pekanbaru Indonesia Using Analytical Network Process (ANP) Approach. International Journal of Academic Research in Business and Social Sciences. 3(8), 215-228.

Hubeis M \& Najib M. 2008. Manajemen Strategik dalam Pengembangan Daya Saing Organisasi. Jakarta (ID): PT Elex Media Komputindo.

[Kementerian KUKM] Kementerian Koperasi dan Usaha Kecil dan Menengah. 2004. Peraturan Menteri Negara Koperasi dan Usaha Kecil Menengah Republik Indonesia Nomor 91 Tahun 2004 tentang Petunjuk Pelaksanaan Kegiatan Usaha Koperasi Jasa Keuangan Syariah. Jakarta (ID): Kementerian Koperasi dan UKM.

[Kementerian KUKM] Kementerian Koperasi dan Usaha Kecil dan Menengah. 2009. Peraturan Menteri Negara Koperasi dan Usaha Kecil Menengah Republik Indonesia Nomor 3 Tahun 2009 tentang Pedoman Umum Linkage Program antara Bank Umum dengan Koperasi. Jakarta (ID): Kementerian Koperasi dan UKM.

[Kementerian KUKM] Kementerian Koperasi dan Usaha Kecil dan Menengah. 2015. Peraturan Menteri Negara Koperasi dan Usaha Kecil Menengah Republik Indonesia Nomor 16 Tahun 2015 tentang Pelaksanaan Kegiatan Usaha Simpan Pinjam dan Pembiayaan Syariah oleh Koperasi. Jakarta (ID): Kementerian Koperasi dan UKM.

[Kementerian KUKM] Kementerian Koperasi dan Usaha Kecil dan Menengah. 2016. Peraturan Deputi Bidang Pengawasan Kementerian Koperasi dan Usaha Kecil dan Menengah Republik Indonesia Nomor 6 Tahun 2016 tentang Pedoman Penilaian Kesehatan Koperasi Simpan Pinjam dan Pembiayaan dan Unit Simpan Pinjam dan Pembiayaan Koperasi. Jakarta (ID): Kementerian Koperasi dan UKM.

[Kementerian KUKM] Kementerian Koperasi dan Usaha Kecil dan Menengah. 2016. Peraturan Deputi Bidang Pengawasan Kementerian Koperasi dan Usaha Kecil dan Menengah Republik Indonesia Nomor 7 Tahun 2016 tentang Pedoman Penilaian Kesehatan Koperasi Simpan Pinjam dan Pembiayaan Syariah dan Unit Simpan Pinjam dan Pembiayaan Syariah Koperasi. Jakarta (ID): Kementerian Koperasi dan UKM.

Kim WC, Mauborgne R. 2005. Blue Ocean Strategy (Strategi Samudera Biru). Jakarta: PT Serambi Ilmu Semesta.

Laldin MA, Furqani H. 2013. Developing Islamic Finance in the Framework of Maqasid al-Shariah Understanding the Ends (Maqasid) and the Means (Wasa'il), International Journal of Islamic and Midle Eastern Finance and Management, 6(4), 278-289 doi:10.1108/IMEFM-05-2013-0057.

McConnell P. 2014. Strategic Risk Management, A Tale of Two Strategies, Journal of Risk and Governance, 3(2), 73-93.

Najib M, Kiminami A. 2011. Innovation, cooperation, and business performance some evidence from Indonesian small food processing cluster. Journal of Agribusiness in Developing and Emerging Economies. 1(1):75-96.

[OJK] Otoritas Jasa Keuangan, Statistik Perbankan Indonesia, Vol. 13(10) Sep 2015. [internet]. [diunduh 2016 Jamuari 15]. Tersedia pada: http://www.ojk.go.id/id/kanal/perbankan/data-dan-statistik/statistik-perbankan- 
indonesia/Documents/Pages/Statistik-Perbankan-Indonesia-september2015/SPI\%20September\%202015.pdf

Pemerintah Republik Indonesia. 2013. Undang-Undang Republik Indonesia Nomor 1 Tahun 2013 tentang Lembaga Keuangan Mikro. Jakarta (ID): Sekretariat Negara

Rangkuti F.2015. Teknik Membedah Kasus Bisnis Analisis SWOT. Jakarta (ID): PT Gramedia Pustaka Utama.

Ridwan Muhammad. 2004. Manajemen Baitul Mal wa Tamwil. Yogyakarta (ID): UII Press.

Sholihin A.I. 2010. Buku Pintar Ekonomi Syariah. Jakarta (ID):PT Gramedia Pustaka Utama.

Tambunan T.T.H. 2009. UMKM di Indonesia. Jakarta (ID): Ghalia Indonesia 